\title{
Routing Selection Strategy Under Reliability Constraints in Optical Network
}

\author{
Linchang $\mathrm{Mei}^{1, \mathrm{a}}$, Qiang Chen ${ }^{1, \mathrm{~b}}$ and Xintong $\mathrm{Liu}^{2, \mathrm{c}}$ \\ ${ }^{1}$ Hebi Electric Power Supply Company of State Grid, Henan 458000, \\ China \\ ${ }^{2}$ North China Electric Power University, Hebei 071003, China

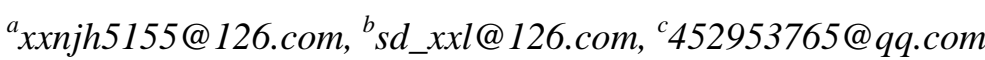

\begin{abstract}
.
Due to the lack of sufficient bandwidth resources and abnormal burst traffics in public network, the available bandwidth is always put in the first place in routing selection algorithm. While services transmitted in electric power optical communication network, such as relay protection, security and stability control, scheduling phone, require not only high real-time but also high channel reliability, which are rarely considered in current routing algorithm. In this paper, a routing selection algorithm under reliability constrains is proposed. The algorithm uses statistical operating data to assess the reliability of the network nodes and links, and provides $k$ shortest paths for different types of services using Dijkstra algorithm and deletion algorithm according to comprehensive cost function which combined bandwidth resource utilization ratio and path reliability.
\end{abstract}

KeyWords: optical network; routing strategies; comprehensive cost function; reliability constraints; deletion algorithm; Dijkstra algorithm

\section{Introduction}

Routing strategy is a method used to find the optimal path from the source node to the destination node. Today, the network has been expanding and the network services have been increasing rapidly. A good routing strategy is one of the important techniques to solve network congestion, ensure quality of services 
and support network for sustainable development.

Complex routing algorithms may use a variety of measurements to choose the optimal route, combine them into a single composite measurement as routing criteria through a certain weighted calculation. The measurements commonly used include path length, delay, hop count, bandwidth, load, communication costs and so on. Ideal routing algorithm must guarantee its accuracy, stability, fairness, be robust to network topology and traffic and ensure its optimization and simplicity.

In considering performance requirements of both bandwidth utilization and network delay, literature [1], [2] and [3] proposed routing algorithms that can balance the distribution of network traffic as much as possible, greatly improved bandwidth utilization. However, they only considered path delay and reliability from the hops point of view, but paid no attention to the affects of operational reliability of facilities and links, while it is also an important to the services that require high reliability.

To meet the different needs of different services in real-time traffic and routing reliability, a routing algorithm under reliability constraints is proposed in this paper. The method, firstly analysis the reliability of all nodes and links using statistical operational data. And then choose the optimal routes for different types of services in considering of the hops, bandwidth resource utilization ratio and the reliability of the path simultaneously.

\section{Routing Strategy}

Routing strategy under reliability constraints includes: getting topology information, reliability analysis of nodes and fiber links, calculating the shortest $k$-path and selecting the optimal path under reliability and bandwidth resource utilization constraints, as follows.

Step 1: Get the topology information and basic data of devices and links in the network, includes device type, speed rating, cable type and length, existing device type, quantity and path information of each service.

Step 2: Compute the reliability of each device and cable link through basic information and operating data.

Through the analysis of the factors that affect the reliability of device and 
cable, and according to <The assurance capabilities assessment of Grid scheduling system safe production>, < State Grid Corporation of eighteen major accident prevention measures(trial)>, reliability evaluation indicator system of the device and optical cable has been shown in Table 1 and Table 2, respectively.

Step 3: Construct the comprehensive cost function with bandwidth utilization ratio, hops and path reliability, as shown in Eq. 1.

$$
C=K_{1} \times C(B)+K_{2} \times C(H)+K_{3} \times C(R) .
$$

Where, $C(B)$ is the maximum bandwidth utilization ratio of the path, which is the maximum value among the cable links in the path set; $C(H)$ is the hop measurement relative to the shortest path, as shown in Eq. $2^{[4]} . C(R)$ is the path reliability metric. $K_{i} \geq 0, \quad i=1 \sim 3$ are the weight factors used to determine the influence degree of each single metric in route selection. The default values can be set to 1 , which represent that the parameters are considered to have the same importance when selecting the routes.

$$
C(H)=1 /(1+\Delta H) \text {. }
$$

Where $\Delta H$ is the hop difference between the current and the shortest path.

Step 4: Find the shortest path from the source to the destination node using Dijkstra algorithm ${ }^{[5]}$, record the path set and the hops. Computing the other $(k-1)$ shortest paths according to deletion algorithm ${ }^{[6]}$.

Calculate the value of comprehensive cost function for each path. Select the optimal path according to the comprehensive cost function.

Table 1 The reliability evaluation indicator system of node device

\begin{tabular}{c|c|c|c|c|c|l|c}
\hline Level 1 & weight & Level 2 & weight & Level 3 & weight & Index Grade & Value \\
\hline $\begin{array}{c}\text { Device } \\
\text { configur-a } \\
\text { tion }\end{array}$ & 0.5 & $\begin{array}{c}\text { Redund-a } \\
\text { ncy }\end{array}$ & 0.6 & & & $\begin{array}{l}1+1 \\
\text { Protection }\end{array}$ & 0.1 \\
\cline { 5 - 7 } & & & & & $1+0$ & 0.9 \\
\hline
\end{tabular}




\begin{tabular}{|c|c|c|c|c|c|c|c|}
\hline & & & & & & Protection & \\
\hline & & \multirow{4}{*}{$\begin{array}{l}\text { Power } \\
\text { system }\end{array}$} & \multirow{4}{*}{0.4} & \multirow{2}{*}{$\begin{array}{c}\text { Power } \\
\text { redundan-cy }\end{array}$} & \multirow{2}{*}{0.5} & Yes & 0.1 \\
\hline & & & & & & No & 0.9 \\
\hline & & & & \multirow{2}{*}{$\begin{array}{l}\text { Battery } \\
\text { quality }\end{array}$} & \multirow{2}{*}{0.5} & Good & 0.1 \\
\hline & & & & & & General & 0.5 \\
\hline \multirow{9}{*}{$\begin{array}{c}\text { Device } \\
\text { operati-on }\end{array}$} & \multirow{9}{*}{0.4} & \multirow{4}{*}{$\begin{array}{c}\text { Enviro-n } \\
\text { ment }\end{array}$} & \multirow{4}{*}{0.6} & Dedust & \multirow{2}{*}{0.6} & Yes & 0.1 \\
\hline & & & & regularly? & & No & 0.9 \\
\hline & & & & \multirow{2}{*}{$\begin{array}{l}\text { Grounding } \\
\text { resistance }\end{array}$} & \multirow{2}{*}{0.4} & $<5 \Omega$ & 0.1 \\
\hline & & & & & & $>5 \Omega$ & 0.9 \\
\hline & & \multirow{5}{*}{$\begin{array}{c}\text { Average } \\
\text { number of } \\
\text { card } \\
\text { failure } \\
\text { annually }\end{array}$} & \multirow{5}{*}{0.4} & & & $50<\mathrm{n}$ & 1 \\
\hline & & & & & & $12<\mathrm{n} \leq 50$ & 0.7 \\
\hline & & & & & & $2<\mathrm{n} \leq 12$ & 0.5 \\
\hline & & & & & & $0.2<\mathrm{n} \leq 2$ & 0.3 \\
\hline & & & & & & $\mathrm{n} \leq 0.2$ & 0.1 \\
\hline \multirow{2}{*}{$\begin{array}{l}\text { Running } \\
\text { duration }\end{array}$} & \multirow{2}{*}{0.1} & & & & & $\leq 10$ years & 0.1 \\
\hline & & & & & & $>10$ years & 0.5 \\
\hline
\end{tabular}

Table 2 The reliability evaluation indicator system of fiber cable

\begin{tabular}{c|c|c|c}
\hline Index & Weight & Index Grade & Value \\
\hline \multirow{4}{*}{ Length } & \multirow{3}{*}{0.3} & $<10 \mathrm{~km}$ & 0.1 \\
\cline { 3 - 4 } & & $10-20 \mathrm{~km}$ & 0.3 \\
\cline { 3 - 4 } & & $20-40 \mathrm{~km}$ & 0.5 \\
\cline { 3 - 4 } & & $>40 \mathrm{~km}$ & 0.7 \\
\hline \multirow{4}{*}{$\begin{array}{c}\text { The number of broken } \\
\text { annually }\end{array}$} & \multirow{3}{*}{0.4} & $50<\mathrm{n}$ & 1 \\
\cline { 3 - 4 } & & $12<\mathrm{n} \leq 50$ & 0.7 \\
\cline { 3 - 4 } & & $2<\mathrm{n} \leq 12$ & 0.5 \\
\cline { 3 - 4 } & & $0.2<\mathrm{n} \leq 2$ & 0.3 \\
\hline \multirow{3}{*}{ Operating duration } & \multirow{3}{*}{0.3} & $\mathrm{n} \leq 0.2$ & 0.1 \\
\cline { 3 - 4 } & & $30<\mathrm{n}$ & 1 \\
\cline { 3 - 4 } & & $20<\mathrm{n} \leq 30$ & 0.5 \\
\hline
\end{tabular}


\begin{tabular}{l|l|c} 
& $\mathrm{n} \leq 5$ & 0.1 \\
\hline If some services are sensitive to one or some of the metrics, the influence of
\end{tabular} other metrics can be ignored, and the value of the corresponding weight is set to 0 . This can meet the requirements of different services in selecting routes.

\section{Simulation Parameters and Results}

The network topology used for simulation is shown in Fig.1. The network contains 8 transmission nodes, 12 links. Assuming capacity of each link is 155Mbits/s. There are 35 services in the network which contains 12 network automation services, 6 relay services, 12 PCM services and 5 other services. The service quantity of each link is shown in Table 3 . The calculation results of bandwidth utilization ratio and reliability risk, according to Table1 and Table 2, are also given in Table 3. The reliability risk of each node is shown in Table 4.

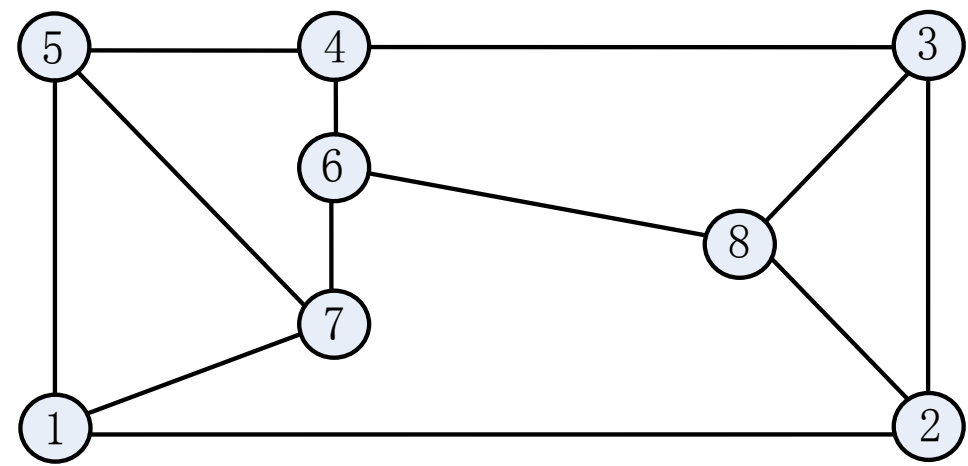

Fig.1 The network topology

Table 3 Service quantity and metric values of each link

\begin{tabular}{c|c|c|c}
\hline Link & Total number of service & $\begin{array}{c}\text { Bandwidth utilization } \\
\text { ratio }\end{array}$ & Reliability risk \\
\hline$l_{12}$ & 11 & 0.142 & 0.28 \\
\hline$l_{15}$ & 16 & 0.206 & 0.28 \\
\hline$l_{17}$ & 6 & 0.077 & 0.16 \\
\hline$l_{23}$ & 9 & 0.116 & 0.22 \\
\hline$l_{28}$ & 3 & 0.039 & 0.4 \\
\hline
\end{tabular}




\begin{tabular}{c|c|c|c}
\hline$l_{34}$ & 9 & 0.116 & 0.22 \\
\hline$l_{38}$ & 3 & 0.039 & 0.28 \\
\hline$l_{45}$ & 10 & 0.129 & 0.30 \\
\hline$l_{46}$ & 0 & 0.0 & 0.22 \\
\hline$l_{57}$ & 5 & 0.065 & 0.34 \\
\hline$l_{67}$ & 1 & 0.013 & 0.34 \\
\hline$l_{68}$ & 0 & 0.0 & 0.22 \\
\hline
\end{tabular}

In Table 3, $l_{i j}$ represents the link between node $i$ and $j$.

Table 4 Reliability risk of each node

\begin{tabular}{c|c|c|c|c|c|c|c|c}
\hline Node & 1 & 2 & 3 & 4 & 5 & 6 & 7 & 8 \\
\hline Reliability risk & 0.1 & 0.1 & 0.13 & 0.1 & 0.1 & 0.16 & 0.13 & 0.18 \\
\hline
\end{tabular}

Suppose we need to set a network automation service from node 1 to node 6 .

According to the Dijkstra algorithm and deletion algorithm, find the 3 shortest paths, as shown in Table 5.

The values of the metrics of the 3-shortest paths are shown in Table 5.Path 1 is the optimal path according to the comprehensive cost function and has the highest reliability, while in consideration of bandwidth utilization ratio, path 3 is the best.

Table 5 Values of the metrics of the 3-shortest paths

\begin{tabular}{c|c|c|c|c|c}
\hline Path label & Path information & Hops & $C(B)$ & $C(R)$ & $C$ \\
\hline 1 & $1 \rightarrow 7 \rightarrow 6$ & 2 & 0.34 & 0.635 & 0.975 \\
\hline 2 & $1 \rightarrow 2 \rightarrow 8 \rightarrow 6$ & 3 & 0.4 & 0.812 & 1.712 \\
\hline 3 & $1 \rightarrow 5 \rightarrow 4 \rightarrow 6$ & 3 & 0.3 & 0.759 & 1.559 \\
\hline
\end{tabular}

\section{Conclusion}

A routing algorithm suitable for optical network under reliability constraints was proposed in this paper. The algorithm took into account with the characteristics of the services carried in special optical transport network. To the services which have high requirements of reliability and real time, both the bandwidth utilization ratio and the reliability of the nodes and links were considered when selecting the optimal path. This can meet the requirement of 
real time and path reliability as well.

\section{References}

[1] Wang Xiao-qin, Zhang Li-fang and Cao Qing-huang: Routing algorithm based on link bandwidth utilization rate. Journal of Computer Applications Vol. 32(9) (2012), p. 2422-2425.

[2] Gu Yun-li, Qian Huan-yan and Xu Xin etc: QoS Anycast Routing Algorithm Based on Bandwidth. Journal of Nanjing University of Science and Technology Vo1. 36(3) (2013), p. 381-385.

[3] Li Yi, Mao Xu, Chen Liang and Li Xi, etc, P.R.C. Patent CN102025628A. (2011) .

[4] Wang-ping Zou: Analysis of QoS-based QBR Routing Selection Algorithm. Journal of Huaihai Institute of Technology (Natural Science Edition) Vol. 22(2) (2013), p. 39-41.

[5] E.W. Dijkstra: A Note on Two Problems in Connexion with Graphs. Numerische Mathematik Vo1. 1(1) (1959), p. 269.

[6] J.A. Azevedo, J.J.E.R.S. Madeira, E.Q.V. Martins and F.M.A. Pires: A Shortest Paths Ranking Algorithm. Proceedings of the Annual Conference AIRO'90, Models and Methods for Decision Support, Operational Research Society of Italy, 1990,p. 1001-1011. 